\title{
MÍDIA E ELEIÇÕES: ANÁLISE DA COBERTURA JORNALÍSTICA PARANAENSE NAS ELEIÇÕES 2006 E 20081
}

\author{
Ana Paula Hedler²
}

\begin{abstract}
Resumo: O artigo analisa a cobertura jornalística do período eleitoral de 2006 e 2008, nos jornais Diário do Norte, Folha de Londrina, Diário dos Campos, Gazeta do Povo e Jornal da Manhã. O objetivo do trabalho é verificar como estes veículos de comunicação trataram as notícias referentes à política e aos demais temas abordados. A metodologia utilizada para a realização da pesquisa é Análise de Conteúdo dos meses que compreendem o período eleitoral (agosto, setembro e outubro). O presente paper apresenta resultados parciais de uma pesquisa mais ampla realizada pelo grupo de pesquisa "Mídia, Política e Atores Sociais", da Universidade Estadual de Ponta Grossa e “Comunicação Política e Opinião Pública”, da Universidade Federal do Paraná.
\end{abstract}

Palavras-chave: Eleições, jornalismo político, cobertura jornalística paranaense.

Resumen: El artículo analiza la cobertura periodística del periodo electoral de 2006 y 2008, en los periódicos Diário do Norte, Folha de Londrina, Diário dos Campos, Gazeta do Povo e Jornal da Manhã. El objetivo del trabajo es verificar como estos vehículos de comunicación trataron las noticias referentes a la política y a los demás temas abordados. La metodologia utilizada para la realización de la investigación es Análisis de Contenido de los meses que comprenden el periodo electoral (agosto, septiembre y octubre). El presente paper presenta resultados parciales de una investigación más amplia realizada por el grupo de investigación "Mídia, Política y Actores Sociales", de la Universida Estadual de Ponta Grossa y "Comunicación Política y Opinión Pública”, de la Universidade Federal do Paraná.

Palabras-clave: Elecciones, periodismo político, cobertura periodística en Paraná.

Abstract: The article analyzes the journalistic cover of the electoral period of 2006 and 2008, in the newspapers Diário do Norte, Folha de Londrina, Diário dos Campos, Gazeta do Povo e Jornal da Manhã. The objective is to verify how these vehicles of mass communication work on news referents to the politics and others subjects related. The methodology used for the achievement of the research is Analysis of Content within the months that comprehend the electoral period (August, September and October). The present paper presents partial results of a broader research carried out by the group of research "Media, Political and Social Actors" of the Universidade Estadual de Ponta Grossa and "Political Communication and Public Opinion" of the Universidade Federal do Paraná.

Key-words: Elections, political journalism, Paraná's journalistic cover.

\footnotetext{
${ }^{1}$ Artigo enviado para Revista Eletrônica de Ciência Política em abril de 2010, aceito para publicação em maio do mesmo ano.

${ }^{2}$ Bacharel em Comunicação Social - Jornalismo pela Universidade Estadual de Ponta Grossa (UEPG/PR), mestranda e bolsista Capes em Ciência Política pela Universidade Federal do Paraná (UFPR). E-mail para contato: ana_hedler@hotmail.com.
} 


\section{INTRODUÇÃO}

Este trabalho tem por objetivo analisar comparativamente a cobertura jornalística das disputas para as prefeituras municipais, realizadas durante o período eleitoral de 2008, e a cobertura jornalística do período eleitoral de 2006, durante a campanha para governador do Estado do Paraná. Para a análise de 2008 foram estudados os jornais Gazeta do Povo, Folha de Londrina, Diário do Norte, Diário dos Campos e Jornal da Manhã. Respectivamente localizados nos municípios de Curitiba capital do Estado, Londrina, Maringá e os dois últimos de Ponta Grossa. Já para a análise da produção jornalística de 2006 foram estudados os periódicos Diário do Norte, Folha de Londrina, Diário dos Campos e Gazeta do Povo.

Os jornais selecionados foram escolhidos por serem considerados os impressos de maior veiculação nas suas respectivas cidades. Não foram utilizados veículos de outras cidades, nesta pesquisa, porque os grupos de pesquisa da Universidade Estadual de Ponta Grossa e da Universidade Federal do Paraná se restringem a analisar os impressos que veiculam em municípios com mais de 200 mil eleitores.

O jornal Diário dos Campos - DC circula em Ponta Grossa e região dos Campos Gerais do Paraná. Foi fundado por Jacob Holzman, sob o título de "O Progresso", em 1907. O maior concorrente direto do DC é o Jornal da Manhã - JM, sendo que este foi fundado em 1954 e passou, em 2007, por uma ampla reforma gráfico/editorial. O JM integra o "Grupo Tribuna de Comunicação". A Folha de Londrina - FL é um jornal de circulação local, na maior cidade do interior do Estado (Londrina), conta com nove cadernos e circula todos os dias da semana, mantendo uma sucursal em Curitiba. Já o Diário do Norte - DN faz parte do grupo de comunicação “O Diário" que conta com a rádio Cultura AM, Dflash, e Diário Online. A Gazeta do Povo GP existe desde 1919, quando Benjamim Lins fundou o jornal em Curitiba. Hoje é considerado o maior jornal do estado do Paraná em tiragem, e tem circulação regional - faz parte do Grupo RPC (Rede Paranaense de Comunicação) juntamente com o Jornal de Londrina, Portal RPC, 98 FM e RPC TV.

O período da análise compreende os meses de agosto, setembro e outubro de 2006 e os mesmos meses de 2008, período considerado o oficial das campanhas eleitorais. A análise do período eleitoral é importante, pois é necessário saber o quê os meios de comunicação de massa estão colocando em debate na esfera pública, uma vez que a partir dos temas que a mídia aborda, o público pode vir a discutir certos assuntos e ao mesmo tempo silenciar outros de relevância social (MCCOMBS E SHAW, 1972). Além do mais, em sociedades democráticas nas quais se exigem a participação dos cidadãos nos processos decisórios, como é o caso das eleições, é imprescindível a 
disponibilização de informação aos eleitores, para que os mesmos possam tomar decisões e formar opinião a respeito dos atores sociais e dos acontecimentos.

A cobertura do período eleitoral tende a apresentar os candidatos envolvidos nas disputas pelo poder, suas propostas e pontos que necessitam de atenção dos políticos para a melhoria do bem-estar dos eleitores como, por exemplo, a implantação de políticas públicas. Como Luis Felipe Miguel reconhece "a mídia é, nas sociedades contemporâneas, o principal instrumento de difusão das visões de mundo e dos projetos políticos; dito de outra forma é o local em que estão expostas as diversas representações do mundo social, associadas aos diversos grupos e interesses presentes na sociedade" (MIGUEL, 2002, p. 6).

$\mathrm{O}$ artigo divide-se em três partes. Na primeira faz-se uma breve introdução aos conceitos e teorias utilizadas para embasar a pesquisa. No segundo item estão os resultados da pesquisa ou observações correspondentes aos mesmos. E, para finalizar, apresentam-se as considerações finais sobre os resultados.

\section{DISCUSSÃo TEÓRICA}

O papel desempenhado pelos meios de comunicação de massa no debate público depende de uma série de fatores, entre eles, o tipo de temas selecionados pelos jornais para serem transformados em notícias e os atores sociais que ganham espaço na cobertura jornalística. É possível imaginar que os critérios de seleção e hierarquização adotados pelos jornalistas no momento em que definem quais temas e abordagens ocuparão espaços privilegiados de visibilidade nos periódicos também interfere no debate público.

Levando em consideração que a globalização tem unido as nações e derrubado barreiras como as do tempo e espaço, facilitando assim que um acontecimento seja noticiado em diversas partes do mundo, no mesmo instante, cresce a influência que a mídia3 tem na sociedade atual, principalmente por agir como "instrumento" de publicização de conteúdos sociais. Para Mauro Wolf a "influência dos media é admitida sem discussão, na medida em que ajudam a estruturar a imagem da realidade social, a longo prazo, a organizar novos elementos da mesma imagem, a formar novas opiniões e crenças" (WOLF, 2006, p. 143). Os meios de comunicação, ainda que não tivessem intenção, têm o poder de pautar os assuntos sobre o que o indivíduo deve pensar (McCOMBS, 1997). Assim sendo, a notícia torna-se o instrumento através do qual

\footnotetext{
3 Mídia é entendida nesse paper como "conjunto de meios de comunicação existentes em uma área, ou disponíveis para uma determinada estratégia de comunicação. Grafia aportuguesada da palavra latina media, conforme é pronunciada em inglês. Media em latim é plural de médium, que significa "meio"”. (RABAÇA; BARBOSA, 2001, p. 490).
} 
grande parte da população se mantém informada e a utiliza como apoio para formar uma opinião a respeito de fatos e pessoas públicas. Isso acontece porque

(...) o jornalismo tornou-se, pois, espaço público de socialização dos discursos particulares, para os confrontos de atualidade, em todos os campos da atividade humana organizada sob a lógica da competição e isso se traduz, com particular intensidade, nos conflitos da política, dos negócios, das idéias, da cultura, dos esportes e das crenças, que recheiam o noticiário de cada dia (CHAPARRO, 2006, p. 33).

Entendendo desta forma, os media tornam-se o lugar no qual se desenvolvem e são discutidos assuntos pertinentes à sociedade, tornando-se um espaço público. Habermas (2003) define a esfera pública como aquela que é contrária à esfera do privado, e é onde se incluem os atores políticos ou, então, a mídia que serve para que o público se comunique. Segundo Habermas, é somente à luz da esfera pública que os assuntos e temas ganham liberdade e continuidade, pois é ali que os temas estão visíveis a todos e estão disponíveis para o debate. Ela designa o espaço no qual os interesses, as vontades e as pretensões dizem respeito a uma coletividade. Já a esfera privada é aquela esfera íntima, da família, na qual são discutidos assuntos relativos à subjetividade.

Dessa forma, os meios de comunicação auxiliam na formação da opinião pública e acabam por agendar os assuntos nos quais as pessoas vão pensar, mesmo que essa não seja a intenção principal dos jornalistas (McCOMBS, 1997). Segundo a hipótese de agenda-setting, os meios de comunicação podem pautar os debates gerados na sociedade a partir do momento em que coloca certos temas em suas páginas, na programação televisiva, no rádio ou na Internet. McCombs e Shaw (1997) acreditam que, a médio e longo prazos, os media ajudam a estruturar a imagem da realidade social, além de organizar os elementos dessa mesma imagem, e a formar novas opiniões e crenças. Segundo Traquina (2001, p. 22), o estudioso McCombs acredita que a "noção básica, primitiva de agendamento é um truísmo", porque caso os meios de comunicação não informem ao público sobre os diversos temas e tópicos de um acontecimento, eles dificilmente existirão na esfera pública, tendendo assim, a permanecerem apenas na agenda pessoal dos envolvidos diretamente com o assunto.

Para Luis Felipe Miguel (2002, p. 11),

O impacto da definição da agenda pelos meios é perceptível não apenas para o cidadão comum, que tende a identificar como mais importantes as questões destacadas pelos meios de comunicação, mas também no comportamento de líderes políticos e de funcionários públicos que se vêem na obrigação de dar uma resposta àquelas questões. 
Os atores políticos contemporâneos utilizam-se dos meios de comunicação como instrumento de divulgação de campanha, com a intenção de tornarem público seus planos, projetos, ideais, propostas, além da filosofia de seus partidos. Isso acontece porque os meios de comunicação de massa são mediadores entre o público e o fazer política e, além disso, "estar na mídia é estar na atualidade" (RODRIGUES, 2002, p. 15). A fim de alcançarem esse objetivo os candidatos e demais integrantes da elite política fazem uso de veículos de comunicação de massa como o rádio, a televisão e os impressos e "de fato, parece cada vez mais distante pensar uma eleição sem a presença, ação e influência da mídia” (GADINI, 2004, p. 16). Para Manin (1995), os políticos atuais chegam ao poder por causa de suas aptidões pessoais e experiência no uso dos meios de comunicação de massa, e não porque estão próximos, ou porque são parecidos, com seu eleitorado.

Porém, nem tudo aquilo que acontece na sociedade torna-se notícia, pois jornalistas e editores fazem uso de critérios de noticiabilidade, os quais funcionam como categorias de seleção. A noticiabilidade passa a ser entendida como um conceito que explica quais fatos sociais possuem aspectos passíveis de se transformarem objeto de atenção dos jornalistas e integrarem o noticiário. Nelson Traquina explica que é possível "definir o conceito de noticiabilidade como um conjunto de critérios e operações que fornecem a aptidão de merecer um tratamento jornalístico [...]" (TRAQUINA, 2005, p. 63). Para Mário Erbolato (1985), os critérios mais significativos são raridade, exclusividade, proximidade e interesse humano.

Como os jornalistas selecionam os temas que serão noticiáveis, muitos assuntos acabam ficando fora da agenda da mídia, o que para a socióloga Elisabeth Noëlle-Neumann pode gerar uma espiral do silêncio. A ideia de espiral do silêncio parte do pressuposto de que quando a pessoa se encontra em situação de instabilidade, e precisa tomar partido para defender sua opinião, se o seu ponto de vista está de acordo com a opinião dominante tende a ser mais fácil se manifestar, caso contrário, a tendência é de que haja um silenciamento da opinião, pois percebendo que seu ponto de vista não é majoritário a pessoa fica menos segura e menos propensa a se expressar (NOËLLE-NEUMANN, 1995).

Além de analisar quando um tema aparece ou não na mídia, é necessário verificar qual é a forma de tratamento que os jornalistas dão à reportagem, porque existem diferentes meios de se retratar o mesmo acontecimento e isso influenciará a maneira como o receptor assimilará a notícia. Segundo Mauro Porto (2000), existem quatro enquadramentos nos quais podemos classificar as reportagens que são corrida de cavalos, personalista, temático e episódico. A corrida de cavalos diz respeito às 
reportagens que mostram avanços e retrocessos das pesquisas de opinião sobre a campanha eleitoral. O enquadramento personalista faz um perfil detalhado de uma personagem, geralmente candidato ao cargo político disputado. O temático é o que mais interessa à pesquisa de cobertura jornalística, porque são as reportagens que se baseiam nas pesquisas, na interpretação de um conjunto de dados e documentos. E, por fim, o episódico indica uma descrição editorial mostrando o que acontece, mas não interpretando o assunto.

Observando os pontos e hipóteses teóricas apresentadas acima, o próximo tópico traz a metodologia de pesquisa utilizada, os principais resultados comparativos entre o período eleitoral de 2006 e de 2008 e finaliza o trabalho com as considerações finais.

\section{RESULTADO COMPARATIVO DAS ELEIÇÕES 2006 E 2008}

A metodologia utilizada para a pesquisa é Análise de Conteúdo (AC). Segundo Herscovitz (2007), a AC já passou por reformulações, mas com o sentido que utilizamos hoje nas pesquisas em comunicação surgiu com Harold Laswell, em 1927. Para Martin Bauer, a Análise de Conteúdo é uma técnica que permite representar quantidades, tipos, qualidades e distinções na cobertura dos jornais, "capaz de produzir inferências de um texto para seu contexto social, de maneira objetivada" (BAUER, 2003). Para Galera e Conde (2005, p. 30), a "perspectiva quantitativa engloba uma série de técnicas de investigação que pretende obter e medir dados sobre a realidade social" e, dessa forma, seu enfoque é mais explicativo. Já "o método qualitativo integra uma informação sobre os fenômenos sociais mais rica e profunda que aquela que se pode obter com a técnica quantitativa”, assim, a análise qualitativa é mais interpretativa e subjetiva. (GALERA; CONDE, 2005, p. 31). Considera-se análise quantitativa, por exemplo, o estudo do número de entradas jornalísticas. Já a análise qualitativa referese à classificação dos formatos e a visibilidade dos temas.

Através da Análise de Conteúdo, a pesquisa analisou 1.918 entradas jornalísticas, ou seja, textos informativos ou opinativos que incluíam o nome de pelo menos um candidato a prefeito dos municípios de Londrina, Ponta Grossa, Maringá e Curitiba, durante o ano de 2008. Já em 2006 foram estudadas 3.619 entradas durante o período eleitoral para governador do estado do Paraná. Durante o período eleitoral de 2006 os jornais deram grande atenção aos candidatos a governador do estado, pois em três meses de coleta de dados foram veiculadas mais de três mil entradas jornalísticas. 
Tabela 1 - Formato das entradas

\begin{tabular}{|l|c|c|c|c|c|c|c|}
\hline Indicador & $\begin{array}{c}\text { Chamada } \\
\text { primeira } \\
\text { página }\end{array}$ & Reportagem & $\begin{array}{c}\text { Charge } \\
\text { infográfico } \\
\text { ilustração }\end{array}$ & $\begin{array}{c}\text { Coluna } \\
\text { assinada }\end{array}$ & $\begin{array}{c}\text { Artigo } \\
\text { assinado }\end{array}$ & Editorial & Total \\
\hline $\begin{array}{l}\text { Diário do } \\
\text { Norte }\end{array}$ & 31 & 90 & 54 & 114 & 4 & 0 & 293 \\
\hline $\begin{array}{l}\text { Folha de } \\
\text { Londrina }\end{array}$ & 2 & 311 & 32 & 264 & 0 & 150 & 759 \\
\hline $\begin{array}{l}\text { Diário dos } \\
\text { Campos }\end{array}$ & 60 & 195 & 98 & 165 & 10 & 11 & 539 \\
\hline $\begin{array}{l}\text { Gazeta do } \\
\text { Povo }\end{array}$ & 46 & 559 & 355 & 748 & 16 & 304 & 2028 \\
\hline Total & 139 & 1155 & 539 & 1291 & 30 & 465 & 3619 \\
\hline
\end{tabular}

Fonte: Grupo de Pesquisa “Mídia, Política e Atores Sociais”, Universidade Estadual de Ponta Grossa.

Na tabela 1 nota-se que o formato mais utilizado, no geral, foi a "Coluna Assinada" e a "Reportagem". Para o jornalismo, a "Coluna Assinada" tem um peso grande, pois ela é um dos meios que mais pautam assuntos e, muitas vezes, é utilizada por outros meios de comunicação, como a televisão e o rádio, para apontar quais temas tendem a ser relevantes e a puxar o debate público. Sendo assim, pode-se dizer que, principalmente, a Gazeta do Povo e o Diário do Norte consideram o período eleitoral relevante para seu público-alvo, pois foram os jornais que mais investiram na opinião de seus colunistas acerca do tema. Isso não significa dizer que os impressos Folha de Londrina e Diário dos Campos não deram atenção à opinião do colunista, porque eles também veicularam em grande parte "Colunas Assinadas", mas preferiam em primeiro lugar, as reportagens - que também são relevantes para o debate público, pois trazem um aprofundamento da notícia, com a ajuda de pesquisa e dados que auxiliam o leitor a formar opinião sobre aquilo que se fala.

Os jornais investiram também na atração visual dos temas ao combinar fotografia, desenho e texto. Para Lima Júnior (2004), isso é importante, pois aquilo que não se consegue explicar apenas com o texto ou com a fotografia explica-se com os infográficos. E os impressos aproveitaram essa vantagem explicativa de infográficos, charges e ilustrações (representaram 17,5\% da cobertura da Gazeta do Povo, 18,18\% das entradas no Diário dos Campos, 18,43\% no Diário do Norte, sendo que o jornal que menos utilizou essa ferramenta foi a Folha de Londrina com 4,21\%). Este jornal priorizou, em terceiro lugar, a opinião do veículo acerca dos temas considerados mais importantes para os editores, pois o editorial teve destaque de 19,76\% da cobertura jornalística do período.

Além de analisarmos qual é o formato que as notícias se encaixam precisamos saber o local em que estas matérias estavam dispostas nas páginas dos jornais, pois cada local na página tem um valor diferenciado que é calculado a partir da visibilidade que dá ao assunto. Assim, é importante salientar que nenhum tema é disposto de 
maneira aleatória na página do jornal e isso faz com a pesquisa analise a posição das entradas.

Tabela 2 - Localização das notícias nas páginas dos jornais

\begin{tabular}{|c|c|c|c|c|c|}
\hline Indicadores & $\begin{array}{l}\text { Diário do } \\
\text { Norte }\end{array}$ & $\begin{array}{l}\text { Folha de } \\
\text { Londrina }\end{array}$ & $\begin{array}{c}\text { Diário dos } \\
\text { Campos }\end{array}$ & $\begin{array}{c}\text { Gazeta } \\
\text { do Povo }\end{array}$ & Total \\
\hline Página Inteira & 8 & o & 2 & 13 & 23 \\
\hline Metade Superior & 67 & 113 & 75 & 39 & 294 \\
\hline Metade Inferior & 27 & 120 & 43 & 26 & 216 \\
\hline Metade Direita & O & 10 & o & 17 & 27 \\
\hline Metade Esquerda & 0 & 7 & 0 & 8 & 15 \\
\hline Quadrante Superior Direito & 54 & 145 & 103 & 598 & 900 \\
\hline Quadrante Superior Esquerdo & 66 & 111 & 143 & 661 & 981 \\
\hline Quadrante Inferior Direito & 28 & 130 & 81 & 323 & 562 \\
\hline Quadrante Inferior Esquerdo & 43 & 123 & 88 & 343 & 597 \\
\hline Total & 293 & 759 & 539 & 2028 & 3619 \\
\hline
\end{tabular}

Fonte: Grupo de Pesquisa "Mídia, Política e Atores Sociais", Universidade Estadual de Ponta Grossa.

A tabela 2 mostra que grande parte das notícias estava colocada nos quadrantes superiores esquerdo e direito, respectivamente, pois das 3.619 entradas, cerca de duas mil estavam na primeira dobra do página. A notícia na primeira dobra da página do jornal é importante, porque ganha mais visibilidade ao estar alocada na parte superior da página. As notícias maiores em centímetros quadrados geralmente estão dispostas nela, resguardando a segunda dobra para notas e matérias menores. Os jornais Diário do Norte, Diário dos Campos e Gazeta do Povo deram preferência ao quadrante superior esquerdo, com 22,52\%, 26,53\% e 32,59\% das notícias alocadas nele, respectivamente. Já a Folha de Londrina preferiu diagramar as notícias sobre os candidatos no quadrante superior direito, ou seja, 19,10\% das entradas estavam nele.

A posição menos utilizada foi a metade da esquerda, porque apenas $0,41 \%$ das notícias foram colocadas ali. Também foram poucas matérias de página inteira, visto que esta posição representa $0,63 \%$ da cobertura jornalística. Para que o tema ganhe destaque de página inteira deve ser considerado pelos editores e jornalistas de grande relevância social e precisa se encaixar nos principais critérios de noticiabilidade, por isso dificilmente notícias relacionadas ao mesmo tema ganharam esse espaço frequentemente.

A terceira tabela traz os temas nos quais os candidatos ao cargo de governador do estado estavam presentes. Percebe-se que em todos os jornais os candidatos, quando apareciam nas páginas, estavam relacionados à "Campanha Eleitoral”, o que confirma a hipótese de que os meios de comunicação de massa fazem uma cobertura mais específica sobre o tema de destaque do momento, que no caso era a disputa eleitoral. 
Tabela 3 - Temática das entradas

\begin{tabular}{|l|c|c|c|c|c|}
\hline \multicolumn{1}{|c|}{ TEMA } & $\begin{array}{c}\text { Diário } \\
\text { do } \\
\text { Norte }\end{array}$ & $\begin{array}{c}\text { Folha de } \\
\text { Londrina }\end{array}$ & $\begin{array}{c}\text { Diário } \\
\text { dos } \\
\text { Campos }\end{array}$ & $\begin{array}{c}\text { Gazeta } \\
\text { do Povo }\end{array}$ & Total \\
\hline Campanha Eleitoral & 272 & 476 & 493 & 1793 & 3034 \\
\hline Político-institucional & 10 & 201 & 18 & 130 & 359 \\
\hline Economia & 1 & 9 & 2 & 24 & 36 \\
\hline Política Social & 4 & 7 & 3 & 23 & 37 \\
\hline Infra-estrutura e meio ambiente & 1 & 18 & 5 & 14 & 38 \\
\hline Violência e segurança & $\mathbf{1}$ & 3 & 2 & 3 & 9 \\
\hline Ético-moral & $\mathbf{1}$ & 5 & 8 & 20 & 34 \\
\hline Política para Esporte, Cultura e Variedades & $\mathrm{O}$ & $\mathrm{O}$ & 2 & 15 & 17 \\
\hline Política Estadual, Nacional, Internacional & $\mathrm{O}$ & $\mathbf{2}$ & 3 & 3 & 8 \\
\hline Outros & 3 & 38 & 3 & 3 & 47 \\
\hline Total & 293 & 759 & 539 & 2028 & 3619 \\
\hline
\end{tabular}

Fonte: Grupo de Pesquisa "Mídia, Política e Atores Sociais", Universidade Estadual de Ponta Grossa.

Os índices de frequência deste tema nos impressos Diário do Norte $(92,83 \%)$, Folha de Londrina (62,71\%), Diário dos Campos (91,46\%) e Gazeta do Povo $(88,41 \%)$ demonstram a importância que deram à cobertura especializada sobre a campanha dos candidatos. Os percentuais do DC e do DN foram quase iguais (mais de 91\%), já na GP essa percentagem também foi elevada (quase 90\%). Sendo que o jornal que menos falou sobre a "Campanha Eleitoral" foi a Folha de Londrina (pouco mais de 60\%), mesmo assim, trouxe bastantes notícias sobre o tema. Esta particularidade do jornal de Londrina mostra que sua linha editorial também deu ênfase ao "Político-Institucional", ou seja, temas que tenham relação com o governo de estado, município, ou federação; com o governador em exercício, com a Câmara dos Deputados e Senado; com a Assembléia Estadual; Poder Judiciário; Partidos ou com outras instituições políticas. O que o torna um jornal com cobertura diferenciada dos demais em relação aos temas trabalhados.

Além de verificar quais os temas nos quais os candidatos estavam presentes é preciso saber qual o enquadramento que as reportagens se classificam, pois eles indicaram como as notícias foram tratadas pelos jornalistas e editores. A tabela quatro mostra que o jornal que mais trouxe reportagens foi a Gazeta do Povo, sendo que, assim como os demais veículos de comunicação, utilizou freqüentemente $o$ enquadramento "Episódico" (80\%). Nesse enquadramento, a matéria restringe-se a relatar os acontecimentos mais recentes da campanha, sem apresentar o enfoque característico dos outros três enquadramentos. São notícias majoritariamente descritivas, orientadas por acontecimentos que geram reações do público, desconsiderando aspectos mais amplos que envolvem esse evento. Trata-se do simples relato de fatos ou de declarações de atores, candidatos ou não, sobre fatos da campanha. 
Tabela 4 - Enquadramento das Reportagens

\begin{tabular}{|l|c|c|c|c|c|}
\hline \multicolumn{1}{|c|}{ Enquadramento } & $\begin{array}{c}\text { Corrida de } \\
\text { Cavalos }\end{array}$ & Personalista & Temático & Episódico & Total \\
\hline Diário do Norte & $9(9,7 \%)$ & $5(5,4 \%)$ & 0 & $79(84,9 \%)$ & $93(100 \%)$ \\
\hline Folha de Londrina & $19(6,8 \%)$ & $7(2,5 \%)$ & $14(5,0 \%)$ & $238(85,61 \%)$ & $278(100 \%)$ \\
\hline Diário dos Campos & $38(20,4 \%)$ & $6(3,2 \%)$ & $22(11,8 \%)$ & $120(64,5 \%)$ & $186(100 \%)$ \\
\hline Gazeta do Povo & $23(4,2 \%)$ & $23(4,2 \%)$ & $63(11,5 \%)$ & $437(80 \%)$ & $546(100 \%)$ \\
\hline
\end{tabular}

Fonte: Grupo de Pesquisa "Mídia, Política e Atores Sociais", Universidade Estadual de Ponta Grossa.

Já o enquadramento "Temático" - mais interessante para a pesquisa - não foi utilizado nenhuma vez pelo Diário do Norte, apenas 5,03\% pela Folha de Londrina, 11,82\% pelo Diário dos Campos e 11,53\% pela Gazeta do Povo. A reportagem com este enquadramento procura interpretar as posições e as propostas dos candidatos sobre aspectos substantivos da campanha, dando ênfase às plataformas partidárias ou aos programas apresentados para diferentes temas pelos candidatos. Ele tenta contextualizar os assuntos da campanha eleitoral, abstraindo-se da própria campanha, por isso torna-se bastante interessante para a pesquisa.

Tabela 5 - Valência dos candidatos em Reportagens

\begin{tabular}{|c|c|c|c|c|c|}
\hline Jornais & Valência & $\begin{array}{l}\text { Roberto } \\
\text { Requião PMDB }\end{array}$ & $\begin{array}{l}\text { Osmar Dias } \\
\text { PDT }\end{array}$ & $\begin{array}{l}\text { Flávio Arns } \\
\text { PT }\end{array}$ & $\begin{array}{l}\text { Rubens Bueno } \\
\text { PPS }\end{array}$ \\
\hline \multirow{4}{*}{$\begin{array}{l}\text { Diário do } \\
\text { Norte }\end{array}$} & Positivo & $1(0,5 \%)$ & 0 & 0 & 0 \\
\hline & Neutro & $187(93,96 \%)$ & $169(99,4 \%)$ & $44(97,7 \%)$ & $64(98,5 \%)$ \\
\hline & Negativo & $11(5,52 \%)$ & $1(0,6 \%)$ & $1(2,3 \%)$ & $1(1,5 \%)$ \\
\hline & Total & 199 (100\%) & $170(100 \%)$ & 45 (100\%) & $65(100 \%)$ \\
\hline \multirow{4}{*}{$\begin{array}{l}\text { Folha de } \\
\text { Londrina }\end{array}$} & Positivo & $20(3,25 \%)$ & $15(3,06 \%)$ & $1(0,7 \%)$ & $5(2,7 \%)$ \\
\hline & Neutro & $534(86,97 \%)$ & $451(92,22 \%)$ & $130(95,6 \%)$ & $176(94,6 \%)$ \\
\hline & Negativo & $60(9,77 \%)$ & $23(4,70 \%)$ & $5(3,7 \%)$ & $5(2,7 \%)$ \\
\hline & Total & $614(100 \%)$ & $489(100 \%)$ & 136 (100\%) & $186(100 \%)$ \\
\hline \multirow{4}{*}{$\begin{array}{l}\text { Diário dos } \\
\text { Campos }\end{array}$} & Positivo & $133(40,67 \%)$ & $111(36,51 \%)$ & $16(17,6 \%)$ & $25(25 \%)$ \\
\hline & Neutro & $143(43,73 \%)$ & $180(59,21 \%)$ & $66(72,5 \%)$ & $66(66 \%)$ \\
\hline & Negativo & $51(15,59 \%)$ & $13(4,27 \%)$ & $9(9,9 \%)$ & $9(9 \%)$ \\
\hline & Total & $327(100 \%)$ & 304 (100\%) & $91(100 \%)$ & $100(100 \%)$ \\
\hline \multirow{4}{*}{$\begin{array}{l}\text { Gazeta do } \\
\text { Povo }\end{array}$} & Positivo & $9(3,64 \%)$ & $10(4,6 \%)$ & $\mathrm{O}$ & $\mathrm{O}$ \\
\hline & Neutro & $213(86,23 \%)$ & $195(89,86 \%)$ & $2(100 \%)$ & $3(100 \%)$ \\
\hline & Negativo & $25(10,12 \%)$ & $12(5,52 \%)$ & $\mathrm{O}$ & O \\
\hline & Total & $247(100 \%)$ & 217 (100\%) & $2(100 \%)$ & $3(100 \%)$ \\
\hline
\end{tabular}

Fonte: Grupo de Pesquisa "Mídia, Política e Atores Sociais", Universidade Estadual de Ponta Grossa.

O candidato que mais apareceu nas páginas dos jornais foi Roberto Requião (PMDB) com 1.387 entradas nos quatro jornais. Uma das possíveis explicações para o número de aparições é o fato de o candidato estar, àquele momento, no cargo de 
governador do Estado, portanto, ser responsável pelo governo paranaense. O jornal que mais veiculou a figura de Requião foi a Folha de Londrina, com 614 entradas. Pode-se dizer que fez uma cobertura neutra, porque em $86,97 \%$ das matérias não tendeu positiva ou negativamente, assim como o jornal GP. Porém, a FL apresentou três vezes mais notícias negativas do que positivas quando falou sobre Requião. Dos quatro impressos analisados, o Diário dos Campos foi aquele mais trouxe chamadas jornalísticas negativas sobre Requião, com 51 (15,59\%). Mas se somarmos as notícias positivas com as neutras percebemos que no geral este candidato teve visibilidade positiva, pois estes índices representam mais de 80\% da cobertura do DC.

Osmar Dias (PDT) apareceu com mais frequência na Folha de Londrina (489 vezes) tendo uma visibilidade neutra (92,22\%). Quanto às notícias negativas, esteve presente em $0,58 \%$ no jornal DN, em 4,70\% no FL, no DC 4,27\% e no GP em 5,52\%. Quanto à imagem positiva, o impresso que mais veiculou positivamente sua imagem foi o DC com 111 matérias ou 36,51\%. Já Flávio Arns (PT) foi o candidato que menos apareceu nos quatro jornais, estando presente apenas 274 vezes nos três meses, sendo que quase 50\% desta aparição se concentrou no jornal Folha de Londrina e 33,21\% no Diário dos Campos. A Gazeta do Povo foi o jornal que menos publicou reportagens com a presença de Flávio Arns (só fez isso duas vezes durante o período da campanha eleitoral). Sua visibilidade foi basicamente neutra, pois nos jornais $D N, F L$ e GP o candidato apareceu mais de 95\% em matérias com essa valência. Só na cobertura do Diário dos Campos o índice é um pouco diferente, porque ele estava presente em 72,5\% entradas neutras, $17,6 \%$ em matérias positivas e 9,9\% em matérias negativas, o que conferiu ao candidato uma imagem positiva. Rubens Bueno (PPS) também teve uma visibilidade positiva, pois assim como Arns, nos jornais Diário do Norte, Folha de Londrina e Gazeta do Povo esteve presente em chamadas neutras mais de 95\% das vezes, e no Diário dos Campos esteve em 25\% das positivas, $66 \%$ em neutras e apenas 9\% em negativas. Bueno apareceu 354 vezes durante o período eleitoral, sendo que 52,54\% das vezes estava na Folha de Londrina, 28,24\% no Diário dos Campos, o,84\% na Gazeta do Povo e 18,36\% no Diário do Norte.

A partir da valência das reportagens, percebe-se que a Gazeta do Povo foi o impresso que menos deu visibilidade para Flávio Arns e Rubens Bueno, concentrando sua cobertura em Roberto Requião e Osmar Dias. Uma possível explicação para este fato é que Requião e Dias eram os principais concorrentes ao cargo. Sendo que a última eleição para governador do estado foi a disputa mais acirrada da história das eleições para governador do estado do Paraná: a diferença entre os votos válidos dos candidatos Roberto Requião e Osmar Dias foi apenas de 0,2\% no segundo turno. 
A Folha de Londrina centrou-se na imagem de Roberto Requião, aparecendo em 80,8\% das matérias publicadas nos três meses (das 759 entradas coletadas ele aparece em 614). Os jornais Diário do Norte e Diário dos Campos cederam um espaço mais equilibrado para Roberto Requião e Osmar Dias e Flávio Arns e Rubens Bueno.

Partindo para o estudo da cobertura das eleições de 2008, analisamos 1.918 entradas nos cinco jornais seguintes: Diário dos Campos, Jornal da Manhã, Diário do Norte, Folha de Londrina e Gazeta do Povo.

Tabela 6 - Formato das entradas nas eleições 2008

\begin{tabular}{|l|c|c|c|c|c|c|c|c|}
\hline Indicadores & $\begin{array}{l}\text { Chamada } \\
\text { primeira } \\
\text { página }\end{array}$ & Reportagem & $\begin{array}{c}\text { Charge } \\
\text { infográfico } \\
\text { ilustração }\end{array}$ & Foto & $\begin{array}{c}\text { Coluna } \\
\text { assinada }\end{array}$ & $\begin{array}{c}\text { Artigo } \\
\text { assinado }\end{array}$ & Editorial & Total \\
\hline $\begin{array}{l}\text { Diário do } \\
\text { Norte }\end{array}$ & 10 & 74 & 3 & 10 & 42 & 20 & 1 & 160 \\
\hline $\begin{array}{l}\text { Folha de } \\
\text { Londrina }\end{array}$ & 3 & 105 & 0 & 2 & 31 & 0 & 3 & 144 \\
\hline $\begin{array}{l}\text { Diário dos } \\
\text { Campos }\end{array}$ & 39 & 161 & 20 & 30 & 187 & 0 & 8 & 445 \\
\hline $\begin{array}{l}\text { Jornal da } \\
\text { Manhã }\end{array}$ & 32 & 208 & 75 & 36 & 104 & 9 & 24 & 488 \\
\hline $\begin{array}{l}\text { Gazeta do } \\
\text { Povo }\end{array}$ & 26 & 242 & 57 & 100 & 248 & 6 & 0 & 679 \\
\hline Total & 110 & 790 & 155 & 178 & 612 & 35 & 36 & 1916 \\
\hline
\end{tabular}

Fonte: Grupo de Pesquisa "Mídia, Política e Atores Sociais", Universidade Estadual de Ponta Grossa.

Através da tabela 6 percebe-se que o formato mais utilizado pelos jornalistas para falar dos candidatos a prefeitos dos municípios de Londrina, Ponta Grossa, Maringá e Curitiba foi a "Reportagem" (41,23\%), diferentemente das eleições de 2006, na qual o formato mais usado foi a "Coluna Assinada”. A reportagem é importante porque analisa e interpreta o fato e é mais do que o simples relato jornalístico de uma matéria. A "Coluna Assinada” também teve destaque na cobertura do período eleitoral de 2008, ficando em segundo lugar no número de utilizações, ou seja, 31,94\% da cobertura.

No geral, o formato menos utilizado foi "Artigo Assinado" com 1,82\% da cobertura do período eleitoral. Ele é o espaço de opinião sobre algum tema do momento, a pessoa que escreve não necessita ser especialista naquele assunto como acontece na coluna, mas o tema deve ser relevante. Pode-se afirmar que a cobertura da Gazeta do Povo e do Diário dos Campos tenderam a ser semelhantes, o que aconteceu também entre os jornais Folha de Londrina, Diário do Norte e Jornal da Manhã. Com relação ao tema das matérias, o que mais apareceu durante a cobertura foi Campanha Eleitoral (88,06\%). Isso prova que os jornais veiculam notícias que têm relação com a atualidade e com os períodos nas quais estão inseridas, no caso ao período eleitoral. 
Todos os jornais deram atenção especial à campanha eleitoral, assim como aconteceu nas eleições de 2006.

Temas importantes para o debate público e para a formação da opinião pública acerca das melhores propostas de políticas públicas dos candidatos foram pouco abordados nos jornais paranaenses estudados, visto que Políticas Sociais, InfraEstrutura e Meio Ambiente, e Violência representaram apenas 2,8\% de toda a cobertura. A análise dos formatos e dos temas veiculados mostra que os impressos têm apresentado as mesmas tendências e padrões de cobertura, visto que nos cinco periódicos o tema que mais apareceu foi Campanha Eleitoral e em segundo lugar foi Político-Institucional, exceto no Diário do Norte que deu visibilidade para InfraEstrutura e Meio Ambiente (11,72\%).

Tabela 7 - Temática das entradas

\begin{tabular}{|l|l|l|l|l|l|l|}
\hline \multicolumn{1}{|c|}{ TEMA } & $\begin{array}{l}\text { Diário do } \\
\text { Norte }\end{array}$ & $\begin{array}{l}\text { Folha de } \\
\text { Londrina }\end{array}$ & $\begin{array}{l}\text { Diário dos } \\
\text { Campos }\end{array}$ & $\begin{array}{l}\text { Jornal da } \\
\text { Manhã }\end{array}$ & $\begin{array}{l}\text { Gazeta } \\
\text { do Povo }\end{array}$ & Total \\
\hline Campanha Eleitoral & 127 & 122 & 406 & 449 & 585 & 1689 \\
\hline Político-institucional & 7 & 10 & 17 & 21 & 71 & 126 \\
\hline Economia & $\mathrm{O}$ & $\mathrm{O}$ & 5 & 1 & 1 & 7 \\
\hline Política Social & 5 & $\mathbf{2}$ & $\mathbf{1}$ & 4 & 12 & 24 \\
\hline Infra-estrutura e meio ambiente & 19 & $\mathrm{O}$ & 3 & 3 & $\mathrm{O}$ & 25 \\
\hline Violência e segurança & $\mathbf{1}$ & $\mathbf{1}$ & $\mathrm{O}$ & $\mathrm{O}$ & 4 & 6 \\
\hline Ético-moral & $\mathbf{2}$ & $\mathbf{9}$ & $\mathrm{O}$ & 3 & $\mathrm{O}$ & 14 \\
\hline Política para Esporte & $\mathrm{O}$ & $\mathrm{O}$ & $\mathbf{2}$ & $\mathrm{O}$ & $\mathbf{1}$ & 3 \\
\hline Cultura e variedades & $\mathrm{O}$ & $\mathrm{O}$ & 3 & 4 & $\mathrm{O}$ & 7 \\
\hline $\begin{array}{l}\text { Política Estadual, Nacional, } \\
\text { Internacional }\end{array}$ & $\mathrm{O}$ & $\mathrm{O}$ & $\mathbf{1}$ & $\mathrm{O}$ & $\mathrm{O}$ & $\mathbf{1}$ \\
\hline Outros & $\mathbf{1}$ & $\mathrm{O}$ & 7 & 3 & 5 & 16 \\
\hline Total & 162 & $\mathbf{1 4}$ & 445 & 488 & 679 & 1918 \\
\hline
\end{tabular}

Fonte: Grupo de Pesquisa "Mídia, Política e Atores Sociais" (UEPG).

Também foi analisado o enquadramento das reportagens veiculadas durante o período eleitoral de 2008 ,como era de se esperar, o enquadramento "Episódico" foi aquele que teve mais presença nas reportagens dos cinco jornais. Esse resultado era esperado, pois como a rotina de produção da notícia é ágil e requer rapidez dos jornalistas, as reportagens transmitidas por eles costumam ser mais descritivas do que analíticas. Mas, isso não significa que o repórter não interprete os dados. De 800 reportagens produzidas nesse período, 482 representaram o enquadramento "Episódico", ou seja, 60,25\% delas foram descrições do andamento das campanhas dos candidatos a prefeitos.

Os jornais trouxeram reportagens interpretativas, mas em menor escala. No geral, as reportagens analíticas aparecem em segundo lugar em número de utilizações, somando-se $21 \%$ do total. Tanto o Diário dos Campos como o Jornal da Manhã utilizaram mais vezes a Corrida de Cavalos à interpretação dos dados. Isso porque de 
208 reportagens que o Jornal da Manhã apresentou e das 161 que o Diário dos campos publicou, respectivamente $32(15,38 \%)$ e $29(18,01 \%)$ delas foram sobre o andamento das pesquisas de opinião.

Tabela 8 - Enquadramento das reportagens na cobertura de 2008

\begin{tabular}{|l|l|l|l|l|l|}
\hline Enquadramento & $\begin{array}{l}\text { Corrida de } \\
\text { Cavalos }\end{array}$ & Personalista & Temático & Episódico & Total \\
\hline Diário do Norte & $9(11,8 \%)$ & $6(7,9 \%)$ & $20(26,3 \%)$ & $41(53,9 \%)$ & $76(100 \%)$ \\
\hline Folha de Londrina & $9(7,9 \%)$ & $13(11,5 \%)$ & $16(14,1 \%)$ & $75(66,4 \%)$ & $113(100 \%)$ \\
\hline Diário dos Campos & $29(18 \%)$ & $8(4,9 \%)$ & $25(15,5 \%)$ & $99(61,4 \%)$ & $161(100 \%)$ \\
\hline Jornal da Manhã & $32(15,4 \%)$ & $7(3,3 \%)$ & $30(14,4 \%)$ & $139(66,8 \%)$ & $208(100 \%)$ \\
\hline Gazeta do Povo & $16(6,6 \%)$ & $21(8,7 \%)$ & $77(31,8 \%)$ & $128(52,9 \%)$ & $242(100 \%)$ \\
\hline
\end{tabular}

Fonte: Grupo de Pesquisa "Mídia, Política e Atores Sociais" (UEPG).

Comparando o enquadramento utilizado na cobertura das eleições de 2006 e das eleições de 2008, percebe-se que foram coberturas semelhantes, visto que em ambas o "Episódico" foi o mais usado pelos repórteres e em segundo lugar ficou o "Temático". A diferença está na quantidade de vezes a menos que foi usado o "Episódico" em 2008, pois em 2006 ele praticamente predominou na cobertura, atingindo quase 80\%, e nas eleições de 2008 as variáveis ficaram em torno de 60,2\%.

A partir do enquadramento é possível perceber a linha editorial que os jornais seguem, pois são os editores que selecionam as temáticas que serão reportagens, mas são os repórteres que interpretam e transcrevem os fatos - por isso a pesquisa cruzou dados do enquadramento dado às reportagens e os atores que nelas estavam envolvidos.

Na tabela 9, o principal candidato ao cargo de prefeito de Ponta Grossa, Pedro Wosgrau Filho (PSDB), quando apareceu em notícias sobre a campanha eleitoral, cerca de $60 \%$ delas foram apenas descritivas, e aproximadamente $13 \%$ receberam maior atenção dos jornalistas com o uso da interpretação dos dados contidos na reportagem. Seu concorrente, Sandro Alex (PPS), recebeu atenção especial na apuração em mais de 15\% das matérias, porém a presença maciça estava nas reportagens apenas descritivas (quase 60\%). Percebe-se que os índices são quase os mesmos em ambos candidatos, o que mostra que o Diário dos Campos não reforçou mais a notícia para um candidato do que para outro. 
Tabela 9 - Enquadramento no Diário dos Campos e atores políticos

\begin{tabular}{|c|c|c|c|c|c|c|}
\hline \multicolumn{3}{|c|}{ Indicadores } & \multicolumn{4}{|c|}{ Temas } \\
\hline \multirow{11}{*}{ 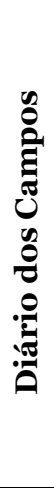 } & \multirow{6}{*}{ 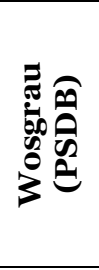 } & Enquadramentos & $\begin{array}{c}\text { Campanha } \\
\text { Eleitoral }\end{array}$ & $\begin{array}{c}\text { Político } \\
\text { Institucional }\end{array}$ & Economia & $\begin{array}{c}\text { Cultura e } \\
\text { Variedades }\end{array}$ \\
\hline & & Corrida de Cavalos & $28(23,9 \%)$ & 0 & $\mathrm{O}$ & $\mathrm{O}$ \\
\hline & & Personalista & $4(3,4 \%)$ & $\mathrm{O}$ & $\mathrm{O}$ & $\mathrm{O}$ \\
\hline & & Temático & $15(12,8 \%)$ & $1(50 \%)$ & $1(100 \%)$ & $\mathrm{O}$ \\
\hline & & Episódico & $70(59,8 \%)$ & $1(50 \%)$ & $\mathrm{O}$ & $1(100 \%)$ \\
\hline & & Total & $117(100 \%)$ & $2(100 \%)$ & $1(100 \%)$ & $1(100 \%)$ \\
\hline & \multirow{5}{*}{ 总 } & Comide de Couro & $06(0000)$ & $\mathrm{O}^{-}$ & $\mathrm{O}^{-}$ & $\mathrm{O}^{-}$ \\
\hline & & $\begin{array}{c}\text { Corrida de Cavalos } \\
\text { Personalista }\end{array}$ & $\frac{20(23,2 \%)}{3(2,7 \%)}$ & 0 & $\frac{0}{0}$ & 0 \\
\hline & & Temático & $17(15,2 \%)$ & 1 (100\%) & $1(100 \%)$ & 0 \\
\hline & & Episódico & $66(58,9 \%)$ & $\mathrm{O}$ & 0 & $\mathrm{O}$ \\
\hline & & Total & $112(100 \%)$ & 1 (100\%) & $1(100 \%)$ & O \\
\hline
\end{tabular}

Fonte: Grupo de Pesquisa “Mídia, Política e Atores Sociais” (UEPG).

A tabela 10 faz o mesmo cruzamento de candidatos, porém com jornal diferente - Jornal da Manhã. A relação é parecida com a cobertura que o Diário dos Campos fez durante os três meses, pois quando Wosgrau foi citado nas reportagens sobre Campanha Eleitoral a cobertura dada foi, na maioria das vezes, apenas descritivas (66\%). Assim como quando Sandro Alex esteve presente nas reportagens do mesmo tema, em $65 \%$ das vezes era apenas descritiva.

Tabela 10 - Enquadramentos no Jornal da Manhã e Atores Políticos

\begin{tabular}{|c|c|c|c|c|c|c|}
\hline \multicolumn{3}{|c|}{ Indicadores } & \multicolumn{4}{|c|}{ Temas } \\
\hline \multirow{11}{*}{ 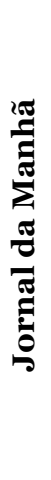 } & \multirow{6}{*}{ 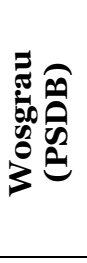 } & Enquadramentos & $\begin{array}{c}\text { Campanha } \\
\text { Eleitoral }\end{array}$ & $\begin{array}{c}\text { Político } \\
\text { Institucional }\end{array}$ & $\begin{array}{l}\text { Política } \\
\text { Social } \\
\end{array}$ & $\begin{array}{c}\text { Infra-estrutura e } \\
\text { meio ambiente }\end{array}$ \\
\hline & & Corrida de Cavalos & $30(21,1 \%)$ & 0 & 0 & 0 \\
\hline & & Personalista & $4(2,8 \%)$ & $\mathrm{O}$ & $\mathrm{O}$ & $\mathrm{O}$ \\
\hline & & Temático & $14(9,9 \%)$ & $\mathrm{O}$ & $\mathrm{O}$ & $2(100 \%)$ \\
\hline & & Episódico & $94(66,2 \%)$ & $5(100 \%)$ & $1(100 \%)$ & $\mathrm{O}$ \\
\hline & & Total & $142(100 \%)$ & $5(100 \%)$ & $1(100 \%)$ & $2(100 \%)$ \\
\hline & \multirow{5}{*}{ 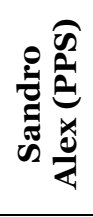 } & Corrida de Cavalos & $27(21,4 \%)$ & 0 & 0 & 0 \\
\hline & & Personalista & $2(1,6 \%)$ & $\mathrm{O}$ & $\mathrm{O}$ & $\mathrm{O}$ \\
\hline & & Temático & $14(11,1 \%)$ & 0 & 0 & $1(100 \%)$ \\
\hline & & Episódico & $83(65,9 \%)$ & $2(100 \%)$ & $1(100 \%)$ & 0 \\
\hline & & Total & $126(100 \%)$ & $2(100 \%)$ & $1(100 \%)$ & $1(100 \%)$ \\
\hline
\end{tabular}

Fonte: Grupo de Pesquisa "Mídia, Política e Atores Sociais” (UEPG).

A maior diferença entre o JM e o DC está nos temas das reportagens, pois no primeiro foi publicada uma reportagem sobre políticas sociais que relacionou os dois principais candidatos, de característica descritiva e outras duas matérias sobre a infraestrutura e meio ambiente que trouxeram uma análise mais crítica, quando Wosgrau (PSDB) e Sandro Alex (PPS) tiveram visibilidade. Mas no restante a cobertura se fez parelha. 
Tabela 11 - Enquadramentos na Folha de Londrina e Atores Políticos

\begin{tabular}{|c|c|c|c|c|c|c|}
\hline \multicolumn{3}{|c|}{ Indicadores } & \multicolumn{4}{|c|}{ Temas } \\
\hline \multirow{11}{*}{ 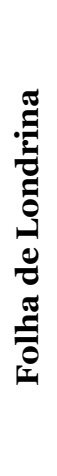 } & \multirow{6}{*}{ 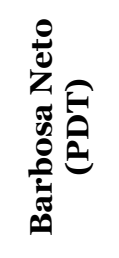 } & Enquadramentos & $\begin{array}{c}\text { Campanha } \\
\text { Eleitoral }\end{array}$ & $\begin{array}{c}\text { Político } \\
\text { Institucional }\end{array}$ & $\begin{array}{l}\text { Violência e } \\
\text { Seguranca }\end{array}$ & Ético e Moral \\
\hline & & Corrida de Cavalos & $7(13,7 \%)$ & 0 & 0 & $\mathrm{O}$ \\
\hline & & Personalista & $3(5,9 \%)$ & $7(100 \%)$ & 0 & 0 \\
\hline & & Temático & $11(21,6 \%)$ & $\mathrm{O}$ & O & $1(33,3 \%)$ \\
\hline & & Episódico & $30(58,8 \%)$ & $\mathrm{O}$ & $1(100 \%)$ & $2(66,7 \%)$ \\
\hline & & Total & $51(100 \%)$ & $7(100 \%)$ & $1(100 \%)$ & $3(100 \%)$ \\
\hline & \multirow{5}{*}{ 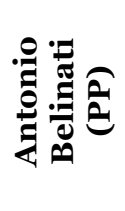 } & Corrida de Cavalos & $9(12 \%)$ & 0 & 0 & 0 \\
\hline & & Personalista & $3(4 \%)$ & $\mathrm{O}$ & 0 & $\mathrm{O}$ \\
\hline & & Temático & $10(13,3 \%)$ & 0 & 0 & $1(14,3 \%)$ \\
\hline & & Episódico & $53(70,7 \%)$ & $1(100 \%)$ & 0 & $6(85,7 \%)$ \\
\hline & & Total & $75(100 \%)$ & $1(100 \%)$ & $\mathrm{O}$ & $7(100 \%)$ \\
\hline
\end{tabular}

Fonte: Grupo de Pesquisa "Mídia, Política e Atores Sociais" (UEPG).

No jornal de Londrina, quando Barbosa Neto (PDT) estava presente em reportagens, elas tenderam a ser mais descritivas, assim como aconteceu com os candidatos de Ponta Grossa. Cerca de 60\% das reportagens sobre Campanha Eleitoral eram descritivas. Algo interessante é que diferente dos candidatos anteriores, os concorrentes Barbosa Neto (PDT) e Antonio Belinati (PP) estavam presentes em reportagens sobre Ética e Moral, o que relaciona os dois candidatos a notícias sobre desvio ou má gestão do dinheiro público e corrupção. Dois terços das reportagens em que Barbosa Neto estava presente eram descritivas e um terço mais aprofundada e com maior crítica sobre o tema. Antonio Belinati apareceu duas vezes mais em reportagens sobre corrupção do que seu concorrente, mas em apenas um sexto das reportagens, houve crítica aprofundada. Barbosa Neto estava presente também no tema Violência e Segurança, o que não aconteceu com Antonio Belinati. Quando o assunto foi Política Institucional, Barbosa Neto esteve relacionado à sua opinião, seu comportamento e perfil, diferente de Antonio Belinati que só apareceu uma vez em reportagem descritiva e não personalista. Na Folha de Londrina percebem-se algumas diferenças de enquadramento temático dependendo do candidato a prefeito que se fala, como é o caso das reportagens sobre política institucional que exploraram mais o comportamento e a opinião de Barbosa Neto e as reportagens sobre corrupção que mostraram de forma descritiva mais Belinati do que seu concorrente.

O jornal de Maringá, diferente do Diário dos Campos e da Folha de Londrina, trouxe o tema Política Social quando noticiou sobre os dois candidatos a prefeito do município com enquadramento "Temático". Isso significa que mesmo reportando apenas uma vez o tema para cada candidato, a cobertura foi neutra, porque deu o mesmo detalhamento de dados e explicação para os dois candidatos. O mesmo aconteceu com o tema Infra-Estrutura Urbana e Meio Ambiente. Quando Silvio Barros (PP) estava presente nas reportagens sobre Política Institucional foi enfocada sua 
personalidade e opinião (66,7\%) já para Enio Verri (PT) a cobertura jornalística foi mais descritiva e com menos opinião do candidato, porque enfocou o enquadramento Episódico (66,7\%).

Tabela 12 - Enquadramentos no Diário do Norte e Atores Políticos

\begin{tabular}{|c|c|c|c|c|c|c|c|}
\hline \multicolumn{3}{|c|}{ Indicadores } & \multicolumn{5}{|c|}{ Temas } \\
\hline \multirow{11}{*}{ 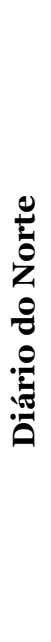 } & \multirow{6}{*}{ 量 } & Enquadramentos & $\begin{array}{c}\text { Campanha } \\
\text { Eleitoral }\end{array}$ & $\begin{array}{c}\text { Político } \\
\text { Institucional }\end{array}$ & $\begin{array}{c}\text { Política } \\
\text { Social }\end{array}$ & $\begin{array}{c}\text { Infra-estrutura } \\
\text { e meio } \\
\text { ambiente }\end{array}$ & $\begin{array}{l}\text { Outros } \\
\text { Temas }\end{array}$ \\
\hline & & $\begin{array}{l}\text { Corrida de } \\
\text { Cavalos }\end{array}$ & $2(7,7 \%)$ & 0 & 0 & 0 & 0 \\
\hline & & Personalista & $1(3,8 \%)$ & $2(66,7 \%)$ & 0 & $\mathrm{O}$ & 0 \\
\hline & & Temático & $4(15,4 \%)$ & 0 & $1(100 \%)$ & $1(100 \%)$ & $\mathrm{O}$ \\
\hline & & Episódico & $19(73,1 \%)$ & $1(33,3 \%)$ & $\mathrm{O}$ & $\mathrm{O}$ & $\mathrm{O}$ \\
\hline & & Total & $26(100 \%)$ & $3(100 \%)$ & $1(100 \%)$ & $1(100 \%)$ & 0 \\
\hline & \multirow{5}{*}{ 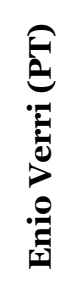 } & $\begin{array}{c}\text { Corrida de } \\
\text { Cavalos }\end{array}$ & $5(11,6 \%)$ & $\mathrm{O}$ & $\mathrm{O}$ & $\mathrm{O}$ & 0 \\
\hline & & Personalista & $1(2,3 \%)$ & $\mathrm{O}$ & 0 & $\mathrm{O}$ & $\begin{array}{c}1 \\
(100 \%) \\
\end{array}$ \\
\hline & & Temático & $10(23,3 \%)$ & $1(33,3 \%)$ & $1(100 \%)$ & $1(100 \%)$ & $\mathrm{O}$ \\
\hline & & Episódico & $27(62,8 \%)$ & $2(66,7 \%)$ & 0 & $\mathrm{O}$ & 0 \\
\hline & & Total & 43 (100\%) & $3(100 \%)$ & $1(100 \%)$ & $1(100 \%)$ & $\begin{array}{c}1 \\
(100 \%)\end{array}$ \\
\hline
\end{tabular}

Fonte: Grupo de Pesquisa “Mídia, Política e Atores Sociais” (UEPG).

Com relação às reportagens sobre "Campanha Eleitoral”, Enio Verri apareceu quase duas vezes mais que Silvio Barros, ou seja, os jornalistas tenderam a utilizar mais o aprofundamento das notícias, fatos e dados quando Verri estava presente nas notícias. A cobertura do $D N$ tendeu mais para Enio Verri quando falou sobre a Campanha Eleitoral, porque ele esteve presente mais vezes em reportagens aprofundadas do que seu concorrente ao governo, porém quanto ao tema "Política Social" e "Infra-Estrutura Urbana e Meio Ambiente" equilibrou as abordagens.

Quando o tema era "Campanha Eleitoral", a GP manteve equilibrada a cobertura entre Beto Richa (PSDB) e Gleisi Hoffmann (PT), porque apresentou o tema com o enquadramento "Episódico" em 52,9\% e 53,7\% respectivamente. Quando o assunto era "Política Institucional" houve uma tendência do jornal a dar mais visibilidade para Beto Richa, porque foram publicadas 29 matérias com ele, enquanto com Gleisi foram apenas duas. Cabe lembrar que Beto Richa era prefeito da capital e concorria a reeleição, o que pode explicar a maior visibilidade do candidato. Podemos afirmar que Beto Richa teve mais espaço de visibilidade do que Gleisi Hoffmann, porque ele apareceu no jornal mais vezes que ela e teve uma cobertura mais aprofundada sobre "Campanha Eleitoral”. 
Tabela 13 - Enquadramentos na Gazeta do Povo e Atores Políticos

\begin{tabular}{|c|c|c|c|c|c|}
\hline \multicolumn{3}{|c|}{ Indicadores } & \multicolumn{3}{|c|}{ Temas } \\
\hline \multirow{11}{*}{ 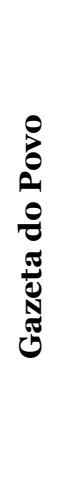 } & \multirow{6}{*}{ 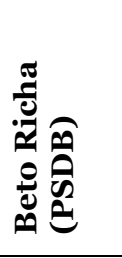 } & Enquadramentos & $\begin{array}{c}\text { Campanha } \\
\text { Eleitoral } \\
\end{array}$ & $\begin{array}{c}\text { Político } \\
\text { Institucional }\end{array}$ & Política Social \\
\hline & & Corrida de Cavalos & $13(10,7 \%)$ & 0 & $\mathrm{O}$ \\
\hline & & Personalista & $8(6,6 \%)$ & $\mathrm{O}$ & $\mathrm{O}$ \\
\hline & & Temático & $36(29,8 \%)$ & $14(48,3 \%)$ & $2(100 \%)$ \\
\hline & & Episódico & $64(52,9 \%)$ & $15(51,7 \%)$ & $\mathrm{O}$ \\
\hline & & Total & $121(100 \%)$ & $29(100 \%)$ & $2(100 \%)$ \\
\hline & \multirow{5}{*}{ 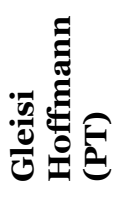 } & Corrida de Cavalos & $12(12,6 \%)$ & 0 & 0 \\
\hline & & Personalista & $3(3,2 \%)$ & 0 & 0 \\
\hline & & Temático & $29(30,5 \%)$ & $1(50 \%)$ & $2(100 \%)$ \\
\hline & & Episódico & $51(53,7 \%)$ & $1(50 \%)$ & $\mathrm{O}$ \\
\hline & & Total & $95(100 \%)$ & $2(100 \%)$ & $2(100 \%)$ \\
\hline
\end{tabular}

Fonte: Grupo de Pesquisa "Mídia, Política e Atores Sociais” (UEPG).

Já quando o tema foi "Política Social" os dois candidatos apareceram da mesma maneira. Com isso, volta-se a afirmar que nem sempre a quantidade maior de aparições nas páginas dos jornais é positiva para o candidato, o que nos leva a analisar a maneira como este candidato está presente nas reportagens.

\section{CONSIDERAÇÕES FINAIS}

A partir da análise comparativa da cobertura jornalística dos anos de 2006 e 2008, pode-se afirmar que, em períodos eleitorais, o jornalismo tende a dar maior atenção ao tema "Campanha Eleitoral", esteja ele relacionado com campanhas municipais ou estaduais, como foi o caso das eleições para governador do Estado do Paraná, em 2008. Isto comprova que os jornais veiculam notícias que têm relação com a atualidade e com os períodos nos quais estão inseridos. Também percebe-se que temas relevantes para o debate público e para a formação da opinião pública, muitas vezes, são silenciados pelos impressos, como aconteceu em 2006 e 2008 com as políticas públicas sociais, as quais tiveram baixa visibilidade.

Jornalistas e especialistas deram grande visibilidade aos políticos que concorreram a cargos públicos nas eleições para prefeito e governador, durante o período eleitoral, visto que publicaram, em 2006, mais de 35\% da cobertura de maneira opinativa e utilizando o formato "Coluna Assinada", e mais de 30\% da cobertura foi aprofundada com a ajuda das reportagens. Já em 2008, aconteceu o inverso: os repórteres investiram mais de 40\% da cobertura jornalística em reportagens, e cerca de 32\% em espaços opinativos, como a "Coluna Assinada”. É necessário ressaltar este 
ponto, porque são formatos considerados importantes nas páginas dos jornais, devido ao seu poder de gerar debate e dar visibilidade a temas que podem a vir a ser pautados por outros veículos de comunicação de massa, como a televisão e o rádio, por exemplo.

A partir do enquadramento e da valência das reportagens podemos observar que a cobertura jornalística tendeu a ser equilibrada, mas conteve diferenças de abordagem devido à linha editorial de cada veículo - o que no geral não prejudicou nenhum candidato e não tendeu favoravelmente a outro. Cerca de $90 \%$ das matérias publicadas, em 2006, foram consideradas neutras, sendo que isto ajuda o leitor a formar uma opinião a respeito do assunto abordado de maneira mais 'objetiva' e menos tendenciosa. Quanto à valência das matérias, nota-se que o Diário dos Campos é o impresso que mais se diferenciou, pois se posicionou mais do que os outros jornais, independentemente do candidato apresentado na notícia, deixando clara a diferença editorial em relação aos demais.

Reitera-se a ideia de que não basta estudar quais temas e atores sociais têm visibilidade nas páginas dos jornais, mas é necessário analisar como é realizada essa tematização. E isso é possível a partir do momento em que se avalia o enquadramento temático de reportagens e as valências das notícias nas quais os atores estão inseridos, em conjunto com outros fatores que fazem parte da rotina de trabalho e produção jornalística, como a diagramação de temas nas páginas dos jornais e o local ocupado pelas notícias. Levando em consideração todos esses aspectos, podemos afirmar que a cobertura do período eleitoral de 2006 e 2008 foi equilibrada, não tendenciosa e teve como característica marcante a semelhança na apresentação do tema "Campanha Eleitoral" entre os jornais estudados.

\section{REFERÊNCIAS BIBLIOGRÁFICAS}

BAUER, Martin; GASKELL, George. (Orgs). Pesquisa Qualitativa com texto, imagem e som: um manual prático. Tradução de Pedrinho A. Guareschi. Rio de Janeiro: Vozes, 2002.

CHAPARRO, Manuel Carlos. Cem anos de assessoria de Imprensa. In: DUARTE, Jorge (Org). Assessoria de imprensa e relacionamento com a mídia: teoria e técnica. 2. ed. São Paulo: Atlas, 2006.

ERBOlATO, Mário. Técnicas de Codificação em Jornalismo. São Paulo: Ática, 1985 .

GADINI, Sérgio Luiz (Org.). Eleições Midiáticas: retratos da disputa política municipal em Ponta Grossa. Ponta Grossa: UEPG, 2004.

GALERA, Maria del Carmen García; CONDE, Maria Rosa Berganza. El método científico aplicado a la investigacion en Comunicacion mediática. In: CONDE, Maria Rosa Berganza; ROMÁN, José Ruiz San (coord.). Investigar en Comunicación: 
guiá práctica de métodos y técnicas deinvestigación en comunicacíon. McGraw-Hill: Madrid, 2005.

HABERMAS, Jürgen. Mudança estrutural da esfera pública. Rio de Janeiro: Tempo Brasileiro, 2003.

HERSCOVITZ, Heloiza. Análise de conteúdo em jornalismo. In: LAGO, Cláudia; BENETTI, Márcia (Orgs). Metodologia de pesquisa em jornalismo. Rio de Janeiro: Vozes, 2007.

LIMA JÚNIOR, Teixeira. Infografia: multimídia avança na vanguarda no campo jornalístico visual. Trabalho apresentado no $\mathbf{V}$ Congreso Iberoamericano de Periodismo en Internet. Salvador: UFBA, 2004.

MANIN, Bernard. As metamorfoses do governo representativo. Revista Brasileira de Ciências Sociais. Associação Nacional de Pós-Graduação e Pesquisa em Ciências Sociais, $\mathrm{n}^{\circ} 29$, ano 10, outubro de 1995.

McCOMBS, Maxwell. Building Consensus: The news media's agenda-setting roles. University of Texas at Austin. Political Communication v. 1 n. 4, p. 433-443, 1997.

MIGUEL, Luis Felipe. Os meios de comunicação e a prática política. Lua Nova: Revista de Cultura e Política. ${ }^{0}$ 55-56. São Paulo, 2002.

NOËLLE-NEUMANN, Elisabeth. La espiral del silencio. Opinión Pública: nuestra piel social. Barcelona, 1995. In: http://www.infoamerica.org/documentos pdf/noelleneumann.pdf, em 10 de abril de 2008.

PORTO, Mauro. A Mídia Brasileira e a Eleição Presidencial de 2000 nos EUA: A Cobertura do Jornal Folha de S. Paulo. Artigo integrante do trabalho "Framing the 2000 U.S. presidential election: The coverage by the Brazilian media", apresentado $\mathbf{5 1}^{\mathbf{a}}$ Conferência Anual da International Communication Association (ICA), Washington D.C., Estados Unidos, 25 a 28 de Maio de 2001.

RABAÇA, Carlos Alberto; BARBOSA, Gustavo Guimarães. Dicionário de comunicação. 2. ed. rev. e atualizada. Rio de Janeiro: Campus, 2001.

RODRIGUES, Malena Rehbein. Imprensa e Congresso ou Como a mídia pauta a política. Brasília: Câmara dos deputados, coordenação de publicação, 2002.

TRAQUINA, Nelson. Porque as notícias são como são. Florianópolis: Insular, 2005 .

WOLF, Mauro. Teorias da Comunicação. Tradução de Maria Jorge Vilar de Figueiredo. Lisboa: Presença, 2006. 